\title{
Prepare Concrete Shielding from Local Materials and Study Linear Attenuation Coefficients
}

\author{
Adel Abdulhadi Jawad ${ }^{1, ~ *, ~ A h m e d ~ F a d e l ~ M k h a i b e r ², ~ K h a l e d ~ H a d i ~ M a h d i ², ~ S a b a h ~ A g e e b ~ K a s s i d ~}{ }^{1}$, \\ Zaidoon Hafed Ibrahem ${ }^{1}$ \\ ${ }^{1}$ Ministry of Science and Technology, Central Laboratory Directorate, Baghdad, Iraq \\ ${ }^{2}$ Department of Physics, College of Education Ibn Al-Haithem, University of Baghdad, Baghdad, Iraq
}

Email address:

adeljawad@yahoo.com (A. A. Jawad)

${ }^{*}$ Corresponding author

\section{To cite this article:}

Adel Abdulhadi Jawad, Ahmed Fadel Mkhaiber, Khaled Hadi Mahdi, Sabah Ageeb Kassid, Zaidoon Hafed Ibrahem. Prepare Concrete Shielding from Local Materials and Study Linear Attenuation Coefficients. American Journal of Environmental Protection. Vol. 10, No. 4, 2021, pp. 100-103. doi: 10.11648/j.ajep.20211004.14

Received: July 5, 2021; Accepted: August 16, 2021; Published: August 24, 2021

\begin{abstract}
The shielding is considered the important ways which dependence on radiation protection as well as distance and time, the concrete is considered important used in shield against gamma ray. Concrete is a relatively low-cost material and it can be handle easily as it can be poured into various, complex shapes. The aim of this research is to verify the linear attenuation coefficient for mixing different types of cement, gravel and sand and choose the appropriate mixture to be used as a shield against gamma rays. In this research, three mixtures consisting of different types of cement available in the local market were used, as they were mixed with different amounts of sand and gravel of different sizes, and the shielding properties of these mixtures were studied against gamma rays using a gamma-ray spectroscopy consisting of $\mathrm{NaI}$ (Tl) detector and two sources, ${ }^{60} \mathrm{Co}$ and ${ }^{137} \mathrm{Cs}$. The results shown in all the samples of the three groups are that the linear attenuation coefficients decrease with increasing the energy. The samples of concrete that contain the type KRISTAL cement have been the highest attenuation than other types of cement where results for attenuation were $(0.30610),(0.22059)$ and $(0.15253)$ for the energies $(662,1137$ and 1332) $\mathrm{KeV}$ respectively. Either the samples which used different size of gravel, that the size of gravel (13 $\mathrm{mm})$ have been heist attenuation that can be concluded the size $(13 \mathrm{~mm})$ of gravel is the best mixture of concrete to attenuation gamma ray in this research.
\end{abstract}

Keywords: Concrete, Gamma Ray Spectrometry, Linear Attenuation Coefficients, Shielding, Sodium Iodide Detector NaI (Tl)

\section{Introduction}

The shielding is consider the important ways which dependence on radiation protection as well as distance and time, mostly the lead used in shielding against gamma ray and X-ray and the concrete is consider important used in nuclear power, $\mathrm{X}$ ray rooms, nuclear medical and uses in Nuclear Power plants, Nuclear Power research, laboratories, and hot cells. [1]

The choice of shielding materials selection is dependent upon exposure rate reduction, kind of source, and final cost effective analysis [2]. In general, there are different materials used to protect against radiation in different applications, for example, polyethylene, glass, epoxy, lead and concrete were used to shield neutrons and gamma rays [3].

Concrete is a relatively low-cost material and it can be handle easily as it can be poured into various, complex shapes. more studies were conducted on the use of cement and other materials in radiation shielding, including in the year (2006) Muhammad Hassan khareta and his team studied special types of reinforced concrete from local materials and the comparison was made between two concrete from two different regions where they studied iron ores and serpentine and black beach sand; by using some of these gravel, it is possible to achieve a reduction in the shielding thickness by about $10-20 \%$ for the gamma rays and neutrons [4]. Akkurt and others used concrete containing smooth and coarse aggregates mixed with barite used as shields against gamma rays. It was concluded that the 
type of gravel was much more important than its quantity by using it in concrete as a shield against gamma rays [5]. V. Fugaru and others studied the shielding properties of gamma rays for some concrete materials, and it was concluded that the linear attenuation coefficient for different types of concrete used decreases with increasing gamma ray energy [6]. F. Demir et al. this group performed accurate measurements to determine the radiation transmission of concrete produced using barite, clmanite, and ordinary aggregate using a beam transfer method for obtaining $0.663 \mathrm{MeV}$ gamma energy from the radioisotope ${ }^{137} \mathrm{Cs}$, in their study finding that linear attenuation coefficients $(\mu)$ It decreases with increasing photon energy of the concrete and the linear attenuation coefficient depends on the photoelectric effect and the Compton scattering of this energy they were concluded that the barite was effective at $0.663 \mathrm{MeV}$ [7].

\section{Materials and Methods}

1- A mold was made with dimensions $(10 \mathrm{~cm} \times 10 \mathrm{~cm} \times 2$ $\mathrm{cm}$ ) (Figure 1) that fits the dimensions of the detector used, and used a gamma ray spectrometry system consisting of NaI (TI) dimension of 3"x3" surrounded by lead shield and connected to a computer equipped with software Genei 2000 was used to record data as shown in Figure 2.

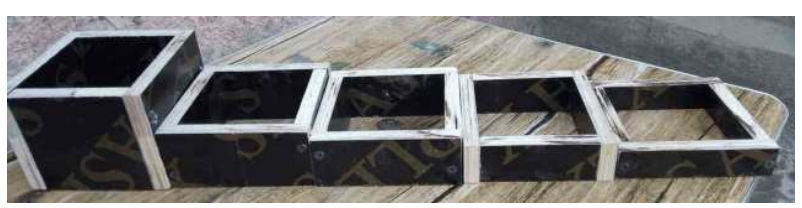

Figure 1. Mold used for pouring concrete.

In this research, two radiation sources were used ${ }^{137} \mathrm{Cs}$ of energy $(662 \mathrm{keV})$ and ${ }^{60} \mathrm{Co}$ of energies $(1173,1332 \mathrm{keV})$. A good engineering position was used to measure the total linear attenuation coefficient, using two collimators lead with a diameter of $1 \mathrm{~cm}$, so that the detector, source, and sample were on one straight line, the distance between the source and the detector was $(10 \mathrm{~cm})$ as shown in Figure 2. The samples measurements were performed at the advanced nuclear physics laboratory at the College of Education, Ibn Al Haytham - University of Baghdad.

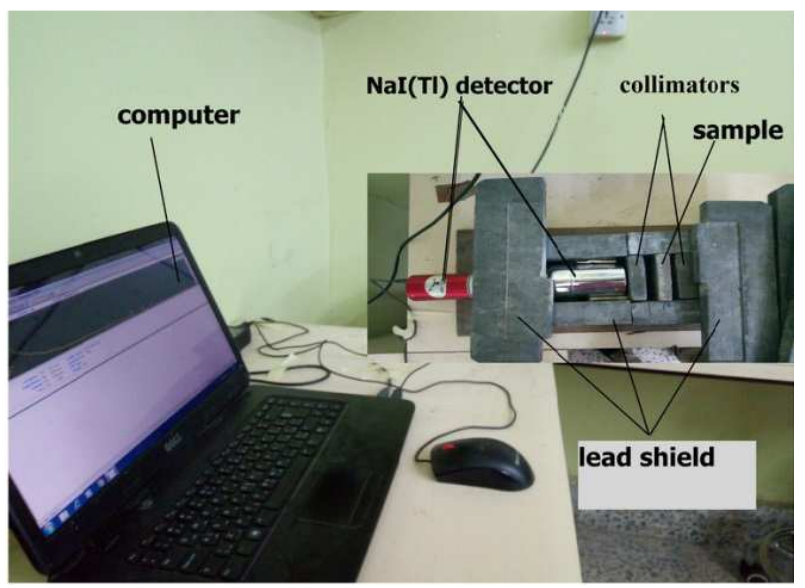

Figure 2. Shows the geometric shape of the gamma ray spectrometry system.

\section{Prepare the Samples}

Three groups of samples were prepared; the first group included the preparation of 9 samples with different thicknesses (1-9) cm, where cement (Al-jesser cement) was used by 1 cement, 2 sand, 2 gravel and 0.5 water.

While the second group included (three samples) where three types of cement were used with equal amounts of cement, gravel, sand and water, at a rate of (1-2-2-0.5), respectively, as shown in Table 1. As for the third group, (four samples) were prepared using a specific type of cement (Al-jesser cement) with quantities of gravel of different sizes and specific quantities of sand and water, at a rate of (2-1-2$0.5)$, respectively, as shown in Table 2 .

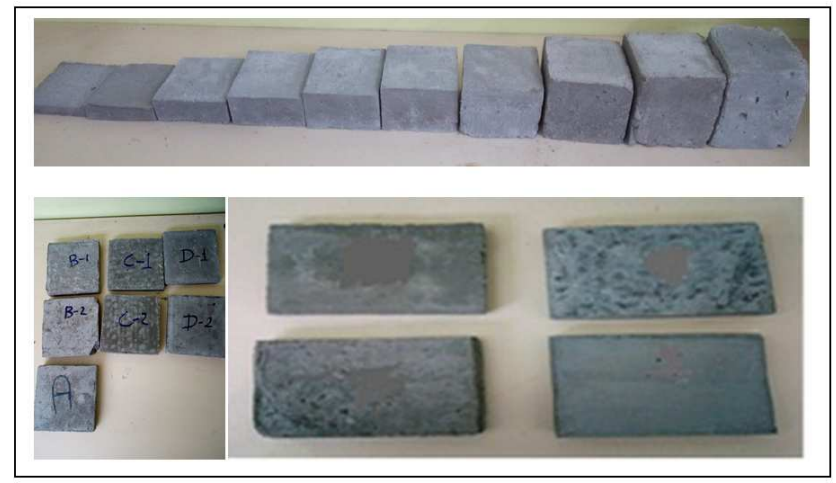

Figure 3. Samples for different types of concrete.

Table 1. Shows the quantity and types of cement mixtures used in the second group.

\begin{tabular}{lllll}
\hline Samples & Type of cement & Amount of cement & Amount of sand & Amount of gravel \\
\hline S1 & Caresta cement & 1 & 2 & 2 \\
S2 & Kerestal cement & 1 & 2 & 2 \\
S3 & Al-jesser cement & 1 & 2 & 2 \\
\hline
\end{tabular}

Table 2. Concrete samples with different gravel sizes.

\begin{tabular}{|c|c|c|c|c|c|}
\hline Samples & Thickness (cm) & The size of the gravel $(\mathrm{mm})$ & $\mu 662$ & $\mu 1173$ & $\mu 1332$ \\
\hline A & 1 & 10 & 0.26348 & 0.13045 & 0.18782 \\
\hline B & 1 & 13 & 0.31170 & 0.17293 & 0.21296 \\
\hline $\mathrm{C}$ & 1 & 14 & 0.32245 & 0.18555 & 0.22992 \\
\hline $\mathrm{D}$ & 1 & 16 & 0.34274 & 0.23872 & 0.26353 \\
\hline
\end{tabular}


Calculation of the linear attenuation coefficient $(\mu)$

Attenuation is the process of removing a photon from a gamma or x-ray beam through absorption effect processes, the Compton scattering and pair production depending on the energy of this radiation [8]. This process can be described by the linear attenuation coefficient $(\mu)$ which can be expressed by the probability of a photon interacting with matter per unit of length [9].

From the Beer Lambert equation, the linear attenuation coefficient can be calculated [10]:

$$
I=I \circ e^{-\mu x}
$$

So that the linear attenuation coefficient $(\mu)$ can be extracted from the following equation:

$$
\mu=\frac{1}{x} \operatorname{Ln} \frac{I}{I}
$$

Where:

$(\mu)$ is the linear attenuation coefficient in $\left(\mathrm{cm}^{-1}\right)$

(I) the intensity of the radiation after penetrating a shield with thickness $\mathrm{x}(\mathrm{cm})$, (Io) the intensity of the radiation from the source without the use of the shield.

\section{Results and Discussion}

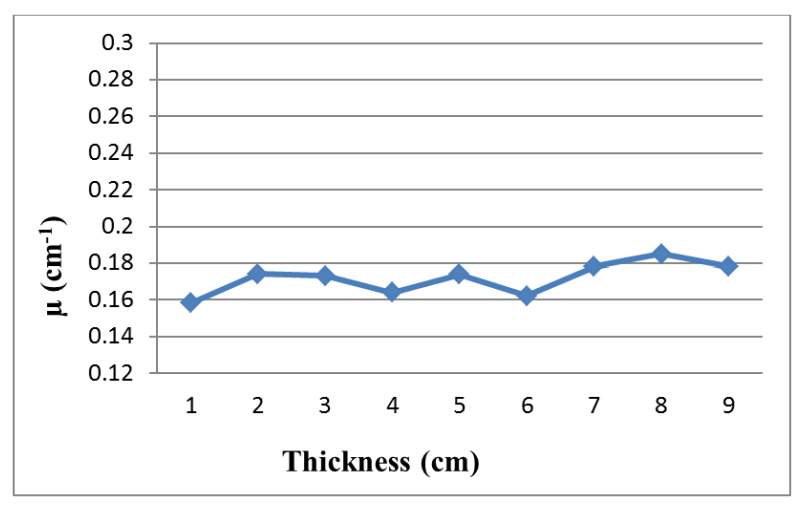

Figure 4. The relationship between linear attenuation coefficient and thickness.

The relationship between the linear attenuation coefficient and the shield thickness is illustrated as shown in Figure 4, it can be seen that the linear attenuation coefficient ranges between values $\left(0.16-0.18 \mathrm{~cm}^{-1}\right)$. [11]

In Figure 5, the relationship between energy and linear attenuation coefficient $\left(\mu \mathrm{cm}^{-1}\right)$ is drawn for three types of cement for mixes of the second group. It can be seen that the linear attenuation coefficient decreases with increasing energy for all samples and that the highest attenuation obtained in the sample (S3) which was used crystal cement as shown in Table 3. Because of the attenuation coefficients of the photoelectric effect, compton effect and the effect of pair production depend largely on the energy of the incident photons [12]. The linearity of the Compton effect is less than the linear attenuation coefficient of the photoelectric effect. Pair production does not occur at all unless the energy is higher than (1.022 MeV). [13]

Table 3. Values of linear attenuation coefficients for different types of cement.

\begin{tabular}{lllll}
\hline Sample name & Cement type & $\boldsymbol{\mu ~ 6 6 2}$ & $\boldsymbol{\mu ~ 1 1 7 3}$ & $\boldsymbol{\mu ~ 1 3 3 2}$ \\
\hline S1 & Carsta cement & 0.20055 & 0.13818 & 0.12845 \\
S2 & Crystal cement & 0.27700 & 0.16518 & 0.13936 \\
S3 & Aljeser cement & 0.30610 & 0.22059 & 0.15253 \\
\hline
\end{tabular}

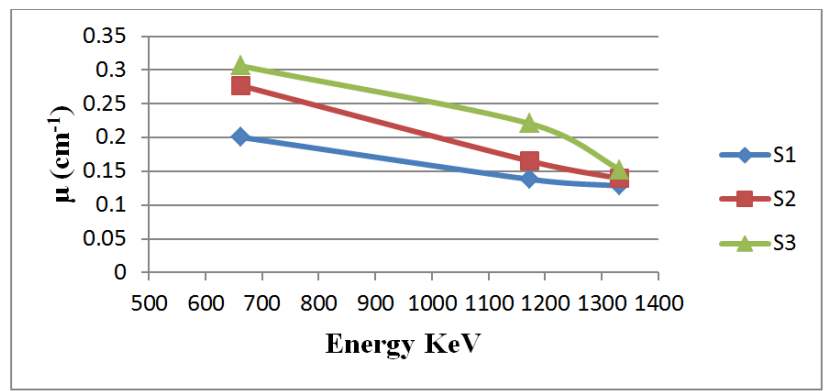

Figure 5. The relationship between linear attenuation coefficient and energy for different types of cement.

In the third group of samples, as the mixture shown in Table 2, where the size of the stones was changed, and 4 gravel sizes were taken. As shown in Figure 6, notice that the linear attenuation coefficient increases with increasing the size of the gravel for all energies. From Figure 6, the attenuation at the energy $662 \mathrm{keV}$ was higher than the energies (1173 and 1332) keV. This indicates that the linear attenuation coefficient decreases with increasing energy. [14]

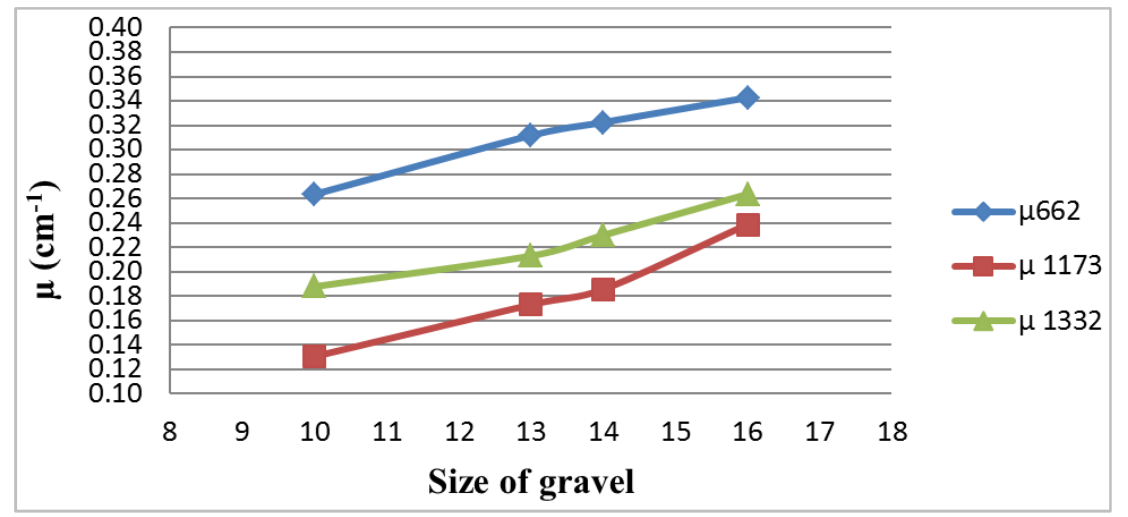

Figure 6. Shows the linear attenuation coefficient for all gravel size. 


\section{The Conclusion}

As noted from the results above in all samples of the three groups, the linear attenuation coefficient decreases with increasing energy, which is required in the attenuation process. The sample (S3) obtained the highest attenuation from other samples and the cement used was Crystal and the sample where the size of the gravel was $13 \mathrm{~mm}$, the attenuation was higher than the other samples, therefore, recommend that the type of cement Crystal and $(13 \mathrm{~mm})$ size of gravel can be used in mixture of concrete used for shielding due to their preference in the attenuation process.

\section{References}

[1] Zongjin, Li. "Advanced concrete technology." Hoboken, New Jersey: John Wiley \& Sons, Inc (2011).

[2] Tekin, H. O et al. (2017). Validation of MCNPX with experimental results of mass attenuation coefficients for cement, gypsum and mixture.

[3] M. F. Kalan, Concrete Radiation Shielding, Longman scientific \&technical, 1989.

[4] Kharita, M. H., Takeyeddin, M., Alnassar, M., \& Yousef, S. (2008). Development of special radiation shielding concretes using natural local materials and evaluation of their shielding characteristics. Progress in Nuclear energy, 50 (1), 33-36.

[5] Akkurt, I., Basyigit, C., Kilincarslan, S., Mavi, B., \& Akkurt, A. (2006). Radiation shielding of concretes containing different aggregates. Cement and Concrete Composites, 283 (2), 153-157.
[6] Fugaru, V., et al. "Gamma ray shielding properties of some concrete materials." Acta Physica Polonica A 127.4 (2015): 1427-1429.

[7] F. Demir, G. Budak, R. Sahin, A. Karabulut, M. Oltulu, and A. Und (2011) "Determination of radiation attenuation coefficients of heavy weight and normal-weight concretes containing colemanite and barite for $0.663 \mathrm{MeV} \gamma$-rays" Annals of Nuclear Energy, vol. 38, pp. 1274-1278.

[8] Reda, S. M. "Gamma ray shielding by a new combination of aluminum, iron, copper and lead using MCNP5." Arab. J. Nucl. Sci. Appl 94. 4 (2016): 211-217.

[9] Jawad, A. A., et al. "Radiation shielding properties of some ceramic wasted samples." International Journal of Environmental Science and Technology (2019): 1-4.

[10] I. Akkurt, C. Basyigit, S. Kilincarslan, B. Mavi (2004) The Shielding Of $\gamma$-Rays by Concretes Produced with Barite.

[11] S. Özavci and B. Cetin (2016) Determination of Radiation Attenuation Coefficients in Concretes Containing Different Wastes. Acta Physica Polonica A, No. 1 Vol. 130.

[12] Kilınçarslan, Ş. (2015, August). Investigation of heavy concretes produced with heavy artificial aggregates. In Special issue of the international conference on computational and experimental science and engineering (ICCESEN 2014) (Vol. 128, No. 2-B).

[13] Obaid, S. S., Gaikwad, D. K., \& Pawar, P. P. (2018). Determination of gamma ray shielding parameters of rocks and concrete. Radiation physics and chemistry, 144, 356-360.

[14] Khalaf, M. A., Ban, C. C., \& Ramli, M. (2019). The constituents, properties and application of heavyweight concrete: A review. Construction and building materials, 215, 73-89. 